\title{
Bite Force and Influential Factors on Bite Force Measurements: A Literature Review
}

Duygu Koca

Arife Dogan ${ }^{b}$

Bulent Bek ${ }^{b}$

\begin{abstract}
Maximum voluntary bite force is an indicator of the functional state of the masticatory system and the level of maximum bite force results from the combined action of the jaw elevator muscles modified by jaw biomechanics and reflex mechanisms. The measurement of bite force can provide useful data for the evaluation of jaw muscle function and activity. It is also an adjunctive value in assessing the performance of dentures. Technological advances in signal detection and processing have improved the quality of the information extracted from bite force measurements. However, these measurements are difficult and the reliability of the result depends on a number of factors, such as presence of pain and temporomandibular disorders, gender, age, cranio-facial morphology, and occlusal factors. In addition to these physiological factors, recording devices and techniques are important factors in bite force measurement. Therefore, one should be careful when comparing the bite force values reported in the research. (Eur J Dent 2010;4:223-232)
\end{abstract}

Key words: Bite force; Bite force recording devices; Temporomandibular disorders.

\section{INTRODUCTION}

Bite force is one indicator of the functional state of the masticatory system that results from the action of jaw elevator muscles modified by the

DDS, Department of Prosthodontics, Faculty of Dentistry, Gazi University, Ankara, Turkey.

b DDS, PhD, Department of Prosthodontics, Faculty of Dentistry, Gazi University, Ankara, Turkey.

Corresponding author: Duygu Koc Department of Prosthodontics, Faculty of Dentistry, Gazi University, 06510, Ankara, Turkey.

Phone: +90 3122034196 Fax : +9031222392 26

E-mail: dtduygukcRahotmail.com duygukoc@agazi.edu.tr craniomandibular biomechanics. ${ }^{1}$ Determination of individual bite force level has been widely used in dentistry, mainly to understand the mechanics of mastication for evaluation of the therapeutic effects of prosthetic devices and to provide reference values for studies on the biomechanics of prosthetic devices. ${ }^{2}$ In addition, bite force has been considered important in the diagnosis of the disturbances of the stomatognathic system. ${ }^{3}$

The bite force measurements can be made directly by using a suitable transducer that has been placed between a pair of teeth. This direct method of force assessment appears to be a convenient 
way of assessing the submaximal force. An alternative method is indirect evaluation of the bite force by employing the other physiologic variables known to be functionally related to the force production. ${ }^{4}$ Electromyographic activity of the surface elevator muscles of the mandible can be picked up from the cutaneous projection of the muscular belly. ${ }^{5}$ In this way, obtained data give an idea for the bite force. The results of some investigations showed a linear relationship between electromyographic activity potentials and direct bite force measurements, especially at a submaximal level. ${ }^{4}$

Several factors influence the direct measurements of the bite force. Thus, different investigators have found a wide range of maximum bite force values. The great variation in bite force values depends on many factors related to the anatomical and physiologic characteristics of the subjects. Apart from these factors, accuracy and precision of the bite force levels are affected by the mechanical characteristics of the bite force recording system. ${ }^{6}$

In this review, we emphasized important factors that affect bite force measurements, such as cranio-facial morphology, age, gender, periodontal support of teeth, signs and symptoms of temporomandibular disorders and pain, and dental status. In addition to these biological factors, mechanical determinants including different recording devices, position of recording devices in dental arch, unilateral or bilateral measurements, using acrylic splints and opening wide of mouth were reviewed.

\section{PHYSIOLOGIC AND MORPHOLOGIC VARIABLES AFFECTING BITE FORCE VALUES}

Cranio-facial morphology

Maximum bite force varies with skeletal measures of the cranio-facial morphology that include the ratio between anterior and posterior facial height, mandibular inclination and gonial angle. It has been explained that bite force reflects the geometry of lever system of mandible. When the ramus is more vertical and the gonial angle acute, elevator muscles exhibit greater mechanical advantage. ${ }^{1,7-10}$

Pereira et $\mathrm{al}^{11}$ have found a negative correlation between bite force and mandibular inclination. This result is consistent with the other studies in which the long-faced type of the cranio-facial morphology has been associated with smaller values of the bite force. ${ }^{8,10}$ The same researchers have also suggested a significant correlation between bite force and muscle thicknesses and between masseter-temporal muscle thickness and facial morphology. ${ }^{11}$ In this respect, Farella et al ${ }^{12}$ have stated that masseter muscles are thicker in shortfaced subjects than in normal or long-faced subjects. From the results of these studies, it seems that short-faced people may exhibit stronger bite force.

Age

The normal aging process may cause the loss of muscle force. ${ }^{13}$ Indeed, the jaw closing force increases with age and growth, stays fairly constant from about 20 years to 40 or 50 years of age, and then declines. ${ }^{1}$ In children with permanent dentition between the ages of 6 and 18, bite force has been significantly correlated with age. ${ }^{14}$

Bakke et $\mathrm{al}^{15}$ have reported that bite force decreases with age after 25 years in females and after 45 years in males. Bite force decreases significantly with age, especially in women. ${ }^{13}$ Shinogaya et $\mathrm{al}^{16}$ have evaluated the effects of age on maximum bite force, average magnitudes of pressure, and occlusal contact areas in elderly (53-62 years) and young (20-26 years) Japanese subjects. The occlusal contact areas and maximum bite force were found to be significantly larger in the senior group than in the young group. Another finding was the smaller average occlusal pressure values in the senior group. However, no difference has been shown in total occlusal force and occlusal force distribution between the older and younger groups because of the larger contact areas of the teeth.

Although the correlation between age and bite force seems to be significant in these studies, it might be assumed that the effect of age on bite force is relatively small. ${ }^{6}$

\section{Gender}

Maximum bite force is higher in males than females. The greater muscular potential of the males may be attributed to the anatomic differences. ${ }^{13,17-19}$ The masseter muscles of males have type 2 fibers with larger diameter and greater sectional area than those of the females. ${ }^{1,20}$ The 
authors have suggested that hormonal differences in males and females might contribute to the composition of the muscle fibers. ${ }^{20}$ In addition, the correlation of maximum bite force and gender is not evident up to age 18. It is apparent that maximum bite force increases throughout growth and development without gender specificity. During the post-pubertal period, maximum bite force increases at a greater rate in males than in females and thus becomes gender-related. ${ }^{21}$

Ferrario et al ${ }^{22}$ have recorded larger bite force values in males and explained this result by their larger dental size. Because the larger dental size presents larger periodontal ligament areas, it can give a greater bite force. In contrast, Wichelhaus et al ${ }^{23}$ have found no significant differences in bite force between males and females. They have suggested that it might be due to the small number of subjects included in their study and to the investigation of functional forces occurring during nocturnal sleep. Even if some authors have found a non-significant gender effect, most studies have confirmed the differences of bite force values between males and females. $7,13,15,17,22$

\section{Periodontal support of teeth}

The loading forces during mastication induced by the masticatory muscles are controlled by the mechanoreceptors of the periodontal ligament. ${ }^{24}$ Therefore, reduced periodontal support may decrease the threshold level of the mechanoreceptors function. ${ }^{25}$ This condition may cause changes in the biting. ${ }^{26}$ Williams et $\mathrm{al}^{27}$ have stated that people with loss of attachment have shown impaired sensory function resulting in reduced control of biting force.

Alkan et $\mathrm{al}^{26}$ have reported that the biting abilities of the subjects with healthy periodontium were significantly higher than those of people with chronic periodontitis. These results are consistent with those of another study in which a positive correlation between reduced periodontal support and decreased biting force has been shown. ${ }^{25}$ At the same time, Morita et $\mathrm{al}^{28}$ have demonstrated an interaction of biting ability and periodontal status; however, they have found little effect of periodontal conditions on biting ability. Contrary to these findings, Kleinfelden and Ludwig ${ }^{24}$ have stated that the reduced periodontal tissue support did not limit bite force with maximal strength in natural dentition. In addition, they stated that the diminished number of periodontal neural receptors may be enough for proper feedback mechanism limiting bite force and chewing forces. The discrepancy between these studies could be attributed to the differences of recording devices and measurement areas.

Laurell and Lundgren ${ }^{29}$ have measured the bite force in dentition restorated with cross-arch bilateral end abutment bridges and found that the magnitude of the chewing force was positively correlated to the areas of the periodontal ligament supporting the bridge abutments. These findings may be explained by the fact that the teeth were splinted together in a relatively stiff construction. An analysis of the correlation between local biting force and local remaining periodontal ligament area of single unsplinted teeth might lead to different results.

\section{Temporomandibular disorders and pain}

Temporomandibular disorders (TMDs) refer to the signs and symptoms associated with pain and functional-structural disturbances of masticatory system, especially of temporomandibular and masticatory muscles, or both. ${ }^{11,30,31}$ It is well known that the etiology of the TMDs is multifactorial. The TMDs are often defined on the basis of signs and symptoms, the most common of which are temporomandibular joint and muscle pain, limited mouth opening, clicking, and crepitation. ${ }^{20}$ Bite force affects muscle efficiency and the development of the masticatory function, so measurement of bite force could be a useful additional method of understanding masticatory function in patients with orafacial diseases. ${ }^{30}$ Therefore, many clinicians have focused on bite force to determine whether or not there is an influence of bite force among TMDs patients. ${ }^{11,14,32}$

Many authors have found significantly lower bite force for the TMDs patients than the healthy control subjects. They have considered that presence of masticatory muscle pain and/or temporomandibular joint (TMJ) inflammation could play a role in limitation of maximum bite force. ${ }^{11,30} \mathrm{Koga}$ wa et $\mathrm{al}^{30}$ have stated that the most frequent cause for the limiting bite force was TMJ pain. In accordance with these studies, Pizolata et $\mathrm{al}^{20}$ have found a positive correlation between decreased bite force and muscle tenderness, and TMJ pain. 
In contrast, Pereira-Cenci et $\mathrm{al}^{14}$ have reported no difference in maximal bite force results between TMDs and healthy control groups. These differences in findings may originate from the severity of the TMDs in patients or different recording techniques.

An important etiological factor causing or contributing to TMDs is bruxism, characterized by clenching and/or grinding the teeth. ${ }^{33,34}$ Gibbs et $\mathrm{a}^{35}$ have compared the bite strength in some bruxists using a gnathodynomometer $12 \mathrm{~mm}$ of height in the molar region. They have reported that bite strength in some bruxists was as much as six times that of non-bruxists. However, Cosme et $\mathrm{al}^{33}$ have measured bite force value with a load transducer with $14 \mathrm{~mm}$ distance in molar region in bruxists and non-bruxists. They have concluded that the two had no different maximal bite force values. In these two studies, although the height and properties of transducers are similar, the severity of bruxism and diagnostic techniques may be different.

\section{Dental status}

Dental status formed with dental fillings, dentures, position and the number of teeth is an important factor in the value of the bite force. ${ }^{36}$ There is a positive correlation between the position and the number of the teeth at both maximal and submaximal bite force. ${ }^{37}$ The number of teeth and contact appears to be an important parameter affecting the maximum bite force. The greater bite force in the posterior dental arch may also be dependent on the increased occlusal contact number of posterior teeth loaded during the biting action. For example, when maximum bite force level increased from $30 \%$ to $100 \%$, occlusal contact areas double. ${ }^{38}$ Bakke et $\mathrm{al}^{15}$ have suggested that the number of occlusal contacts is a stronger determinant of muscle action and bite force than the number of teeth.

Kampe et al $^{39}$ have analyzed measurements of occlusal bite force in subjects with and without dental fillings at molar and incisor teeth. The subjects with dental fillings have shown significantly lower bite force in the incisor region. Based on data obtained in that study, they have proposed that it might be hypothetically due to the adaptive changes caused by the dental fillings.

Miyaura et $\mathrm{al}^{40}$ have compared maximum bite force values in subjects with complete denture, fixed partial denture, removable partial denture and full natural dentition groups. Whereas the individuals with natural dentition have shown the highest bite forces, the biting forces have been found to be 80,35 , and $11 \%$ for fixed partial dentures, removable partial denture and complete denture groups, respectively, when expressed as a percentage of the natural dentition group.

Lasilla et $\mathrm{al}^{37}$ have compared bite force in complete denture, partial denture and natural dentition. Their results are consistent with those of Miyaura et $\mathrm{al}^{40}$ who have found the greatest bite force in the natural dentition group. Moreover, they have found decreased bite force in areas of negative alveolar process and they have stated that there was a positive correlation between the bite force and the height of the alveolar process.

Fontijn-Tekamp et $\mathrm{al}^{41}$ have compared bite force values in implant-supported and root-retained overdentures, full dentures and natural dentition groups. At the maximum bite force level, subjects with dental implant-supported overdenture exerted forces significantly higher than those of full denture group (both with low and high mandible) and root-retained overdenture group. Nevertheless, maximum bite forces exerted by the implant group were still lower than those of the dentate subjects. ${ }^{41}$

\section{THE EFFECT OF THE RECORDING DEVICES AND TECHNIQUES ON BITE FORCE}

Recording devices

The concern on the intraoral force has a long history. ${ }^{42}$ In the related research, a wide range of methods and devices for the determination of bite forces has been reported. These devices vary from simple springs to complex electronic devices.

The first experimental study defining the intraoral forces was performed by Borelli in 1681 who designed a gnatodynamometer. ${ }^{42} \mathrm{He}$ attached different weights to a cord, which passed over the molar teeth of the open mandible, and with closing of the jaw, up to $200 \mathrm{~kg}$ were raised. ${ }^{35}$ Black made the first scientific examination of forces in 1893. Black reached to his outcomes by designing a new type of gnatodynamometer. ${ }^{42}$ Subsequently, several researchers continued to investigate this subject and designed the lever-spring, manometer-spring and lever, and micrometered devices. ${ }^{42,43}$ Today, sensitive electronic devices are used. Such instruments are both accurate and precise enough for common load measuring 
purposes. The function of all modern instruments is based on the electrical resistance action of the strain-gages and the most of them are able to record force levels in the range of $50-800 \mathrm{~N}$ with an accuracy level of $10 \mathrm{~N}$ and $80 \%$ precision. ${ }^{2}$

Gnatodynamometers have been used to measure bite force for a long time and some investigators use strain-gages mounted dynamometer for recordings. ${ }^{44,35}$ A digital dynamometer has been developed. This appliance uses electronic technology and consists of the bite fork and digital body. Its high precision load cell and electronic circuit for indicating force provide precise measurements. ${ }^{20,45}$ Kogawa et al ${ }^{30}$ have evaluated maximal bite force in the temporomandibular disorder patients using a digital dynamometer (model IDDK) with a capacity of $100 \mathrm{kgf}$ and a $14.6 \mathrm{~mm}$ of height. In their study, the mean maximal bite force in control subjects has been found as $338 \mathrm{~N}$ which is parallel to that of other studies.

Recently, deformation-sensitive piezoelectric film has been employed as a force detection recording system. ${ }^{43,46}$ Deformation of piezoelectric film generates an electrical signal, which varies with the force applied to the film. Due to generated electrical signal is a very small electrical current, an amplifier is designed to amplify the piezoelectrical signal. ${ }^{46}$ Lasilla et $\mathrm{al}^{37}$ have used this device in which the current was brought to a digital recorder, and the value could be read either directly or with help of a graphic recorder. Baba et $\mathrm{al}^{46}$ and Takeuchi et $\mathrm{al}^{43}$ have connected the detector directly to an amplifier and then to a threshold-detection circuit in which the output signal was sent to a computer.

Floystrand et al ${ }^{47}$ have introduced a novel miniature bite force recorder. It was a semiconductor in the shape of a silicon beam that served as a sensory unit. Loads on the sensor produce a proportional alteration in the two resistors and leads to electric changes in the circuit. Its calibration test has shown that bite forces in 10 to $1000 \mathrm{~N}$ range good reliability. Similarly, Fernandes et $\mathrm{al}^{2}$ have used conductive polymer pressure-sensing resistors. It had a diameter of $12 \mathrm{~mm}$ and the thickness of $0.25 \mathrm{~mm}$ and consisted of two conducting interdigitated electrodes on a thermoplastic sheet which faced a second sheet coated with a semiconductive polyetherimide ink.

A quartz force transducer has also served as a sensory unit on which the results of clenching action are shown on a liquid crystal display
(LCD). ${ }^{17,48,49}$ Waltimo and Könönen ${ }^{17}$ have reported that the bite forces in the 113-1692 N range could be recorded with good reliability with this device; this device has been described as a good tool for bite force measurement.

The most widely accepted recording device is the strain-gage bite force transducer. ${ }^{46,50-56}$ The strain-gage bite force transducer is available in different heights and widths. Ferrario et $\mathrm{al}^{22}$ and Kogawa et $\mathrm{al}^{30}$ have measured bite force with $4 \mathrm{~mm}$ height and $5 \times 7 \mathrm{~mm}$ wide strain-gaged transducer. Calibration of the instrument was performed at room temperature between 0 and $350 \mathrm{~N}$, with a \pm $2 \%$ error. The deviation from linearity with load of $300 \mathrm{~N}$ was $\pm 7.3 \%$ and with load of $350 \mathrm{~N}$ was $\pm 9 \%$. A large variability of bite force has been found to be ranked between $446 \mathrm{~N}$ and $1221 \mathrm{~N}$.

Another recording device is the dental prescale system which consists of a horse-shoe shaped bite foil of a pressure-sensitive film and a computerized scanning system for analysis of the load. When the force is applied to occlusal contact, a graded colour is produced by the chemical reaction. The exposed pressure-sensitive foils (PSF) are analyzed in the occlusal scanner. The scanner reads the area and colour intensity of the red dots to assess occlusal contact area and pressure. Finally, it calculates occlusal loads automatically. Two types of pressure sensitive sheets are available: Type R (97 $\mu \mathrm{m}$ thick) and type W labout 800 $\mu \mathrm{m}$ thick). Each type of sheet is further divided into two sub-types, $30 \mathrm{H}$ and $50 \mathrm{H}$. The $30 \mathrm{H}$ sheet is used for a range of 30 to $130 \mathrm{kgf} / \mathrm{cm}^{2}$, and the 50 $\mathrm{H}$ sheet for a range of 50 to $1200 \mathrm{kgf} / \mathrm{cm}^{2} .16,33,38,57-61$

Shinogaya et $\mathrm{al}^{16}$ have compared total occlusal load measured with PSF and conventional unilateral strain-gage transducer (UT). Maximum bite forces have been recorded with strain-gage transducer placed on first mandibular molars in 6-7 mm bite opening. Horse-shoe shaped pressure-sensitive foil (Dental Prescale $50 \mathrm{H}$, type $\mathrm{R}$ ) is $0.097 \mathrm{~mm}$ of thickness and maximum bite forces are recorded in intercuspal position. The thin pressure sensitive foil gives the possibility of calculating the bite force from every tooth in recordings with minimal disturbance to the occlusion. In the conventional type of this system where the total jaw closing force is measured at specific points on the dentition, the occlusion is distorted by the unavoidable jaw separation and reduces occlusal support caused by the equipment. Some of the differences between total maximum UT force 
and maximum PSF force have been explained by a technical limitation in computerized scanning apparatus of the dental prescale system. However, despite the difference in absolute values of closing force, the total maximum PSF force and the UT force have been found to be correlated; mean PSF total force, PSF force at first mandibular and UT force have been recorded as $1109 \mathrm{~N}, 148 \mathrm{~N}$, $553 \mathrm{~N}$, respectively. According to Shinogaya et al, ${ }^{16}$ a bite force measuring system such as the dental prescale system using thin pressure-sensitive film (approximately $0.1 \mathrm{~mm}$ ) is superior to ordinary measuring systems using strain-gage transducer. This outcome has been explained by two factors. First, bite force can be measured close to intercuspal position, which provides a better opportunity to estimate bite force under natural conditions. Second, the load distribution over the dentition can be studied at the same time. ${ }^{16,62}$

Fernandes et $\mathrm{al}^{2}$ have compared the bite force using a strain-gaged bite fork and a conductive polymer pressure-sensing resistor (force-sensing resistor). The bite force values obtained from these two have shown statistically significant differences in bite force levels ranging from 50 to 300 $\mathrm{N}$. The reliability of the sensor to record reproducible force levels between two loading series found to be $93 \%$. The results of in situ loading tests have shown that the novel bite force sensor is able to record intraoral forces with sufficient clinical accuracy and precision. However, the investigators have pointed out some problems associated with bite force sensor. The most important one is the nonlinear and load-rate dependent properties of the sensor that could be explained partly by a certain degree of nonlinearity of the force sensing resistor and damage of the surface material of the sensor. Other studies using force sensing resistor have also reported the presence of hysteresis and nonlinear relationships.

Position of recording device in dental arch

Bite force varies in different regions of the oral cavity. ${ }^{22}$ The more posteriorly the transducer is placed in the dental arch, the greater the bite force. ${ }^{63}$ It has been explained by the mechanical lever system of the jaw. ${ }^{4,21}$ In addition, greater bite force can be tolerated better in posterior teeth, because of the larger area and periodontal ligament around posterior teeth roots. ${ }^{63}$

Indeed, different positions of the transducer in dental arch may influence the different muscles that are involved in force production. If the transducer is placed anteriorly between the incisor teeth, with a resultant mandibular protrusion, the masseter muscle will produce most of the force together with the medial pterygoid muscle. If the bite force transducer is more posteriorly placed, then anterior fibres of the temporalis muscle will become more active and hence make a greater contribution to the effort. ${ }^{63}$

Unilateral and bilateral measurements

Another factor influencing the value of the bite force is the recording side involved: unilateral or bilateral application. Most of the studies have shown that bite force during bilateral clenching is larger than during unilateral clenching. b,15,16,38 $^{2}$

Bakke et $\mathrm{al}^{15}$ have applied conventional force transducers in healthy subjects during both unilateral and bilateral clenching. Bilateral total bite force has been measured in healthy subjects and found to be $40 \%$ larger than unilateral clenching on just one force transducer. Shinogaya et $\mathrm{al}^{16}$ have compared bilateral and unilateral bite force measurements using different transducers. They have employed a pressure-sensitive foil $10.1 \mathrm{~mm}$ thick) for bilateral clenching and a conventional force transducer (6-7 $\mathrm{mm}$ thick) for unilateral clenching. They have concluded that bite force increased by about $100 \%$ and masseter activity increased by about $50 \%$ during bilateral clenching compared to unilateral clenching.

Van Der Bilt et $a^{6}{ }^{6}$ have measured bite force and jaw muscle activity during bilateral and unilateral maximum clenching and found 30\% larger bilaterally measured bite force using strain-gage transducer. Moreover, activities of both right and left masseter and anterior temporal muscles have been reported as 30\% larger in bilateral measurement than unilateral measurement. They have pointed out that masseter muscles' activity showed no significant differences in the unilateral clenching experiments; however, the activities of right and left temporal muscles differed significantly during unilateral clenching: loaded side showed significantly more muscle activity.

Theoretically, the jaw muscles should be able to generate a unilateral bite force equal to the force obtained during bilateral clenching. The force per side is larger when measured unilaterally, compared with half of the force measured bilaterally. The lower jaw muscle activity and bite force obtained during unilateral clenching as 
compared to bilateral clenching may be a result of inhibition by periodontal and joint receptors. In order to avoid damage to the teeth, inhibition by periodontal receptors will prevent excessively high muscle activities and strong bite forces. ${ }^{6}$ Van Eijden $^{64}$ has stated that during unilateral clenching, which is highly asymmetric activity, the force at the balancing side joint would be larger than the force at the working side. Thus, inhibition by joint receptors at the non-loaded side might limit joint forces. ${ }^{6}$

\section{Using acrylic splints}

Acrylic appliances may be used for protecting dental cusps and for avoiding dental fracture during maximum clenching. Tortopidis et $\mathrm{al}^{63}$ have used acrylic appliances in contact with the metal faces of the strain-gage transducers to minimize the risk of fracturing teeth when biting hard on the transducer. In addition, when the subject bites the hard metal surface of transducer, the neuromuscular reaction of subject generates irregular movements that prevent maximum bite force. In this situation, acrylic splints provide a comfortable surface for maximum bite force. ${ }^{2,63}$ Besides these advantages, these appliances can provide a standard position of the transducer for each individual, for each session. ${ }^{63}$

Waltimo and Könönen ${ }^{65}$ have used acrylic splints to compare bite forces between a single tooth and multiple teeth. Since the occlusal splint is extended to the molars, increase of maximum biting force is due to the additional force from the molar teeth transmitted to the strain-gage via the splint. ${ }^{47}$ It can be suggested that the larger periodontal area and the greater bite force can be achieved. Kleinfelder and Ludwig ${ }^{24}$ have compared the bite force values in patients with and without splinting by using a strain-gage transducer. Their findings are in good agreement with those of Waltimo and Könönen ${ }^{65}$ who stated the use of acrylic splints could increase bite force values.

\section{Opening wide of mouth}

An increase in the vertical dimension may lead to some changes in the orofacial structures li.e., jaw elevator muscles, temporomandibular joints and periodontium). It is stated that such changes in vertical dimension alter the length of the main jaw elevator muscles and the position of the man- dibular head in the fossa temporalis. Thus, they may affect the masticatory function, resulting in the bite force values. ${ }^{19}$

A previous study has stated that when bite force values were kept constant, electromyographic activity of masseter muscle decreased with increasing of jaw opening. Similarly, when masseter muscle activity levels were kept constant, maximum bite force magnitudes have been recorded between 15 and $20 \mathrm{~mm}$ anterior vertical jaw opening. ${ }^{66}$ In another study, the maximum incising force has been found to be greatest at approximately 17 $\mathrm{mm}$ of incisal opening. It has been stated that as the jaw separation is decreased or increased from this optimum opening, the strength of the maximum incising force decreased. ${ }^{67}$

Lindauer et $\mathrm{al}^{66}$ evaluated the changes in vertical jaw opening affecting the relative contributions of masticatory muscles for bite force production. When bite force was consistent, electromyographic activity increased per unit of force production was relatively high at the smaller degrees of jaw opening, EMG activity has decreased between 9 and $11 \mathrm{~mm}$ of opening, and increased again by 12 $\mathrm{mm}$ of opening. Manns et $\mathrm{a}^{68}$ have recorded minimum activity at jaw openings between 15 and 20 $\mathrm{mm}$ measured anteriorly, essentially equivalent to the 9-11 $\mathrm{mm}$ openings calculated at the molar region in the experiment. These studies clearly indicate that the population mean for developing the strongest bite force has been between 14 and 20 mm of jaw separation. ${ }^{67}$

\section{CONCLUSIONS}

Measurement of bite force has been a reliable method of assessing the biomechanical properties of masticatory system and the prosthetic treatment. However, one should consider other effective factors when comparing bite force measurement in research.

\section{REFERENCES}

1. Bakke M. Bite force and occlusion. Semin Orthod 2006;12:120-126.

2. Fernandes CP, Glantz PJ, Svensson SA, Bergmark A. A novel sensor for bite force determinations. Dent Mater 2003; 19:118- 126.

3. Calderon Pdos S, Kogawa EM, Lauris JR, Conti PC. The influence of gender and bruxism on the human maximum bite force. J Appl Oral Sci 2006;14:448-453. 
4. Ferrario VF, Sforza C, Zanotti G, Tartagilia GM. Maximal bite force in healthy young adults as predicted by surface electromyography. J Dent 2004;32:451- 457.

5. Castroflorio T, Bracco P, Farina D. Surface electromyography in the assessment of jaw elevator muscles. J Oral Rehabil 2008;35:638-645.

6. Van Der Bilt A, Tekamp FA, Van Der Glas HW, Abbink JH. Bite force and electromyograpy during maximum unilateral and bilateral clenching. Eur J Oral Sci 2008;116:217-222.

7. Braun S, Bantleon HS, Hnat WP, Freudenthaler, Marcotte MR, Johnson BE. A study of bite force, part 1: Relationship to various physical characteristics. Angle Orthod 1995;65:367-372.

8. Braun S, Bantleon HP, Hnat WP, Freudenthaler JW, Marcotte MR, Johnson BE. A study of bite force, part 2: Relationship to various cephalometric measurements. Angle Orthod 1995;65:373-377.

9. Castelo PM, Bonjardim LR, Pereira LJ, Gavião MBD. Facial dimensions, bite force and masticatory muscle thickness in preschool children with functional posterior crossbite. Braz. Oral Res 2008;22:48-54.

10. Ingervall $B$, Minder $C$. Correlation between maximum bite force and facial morphology in children. Angle Orthod 1997;67:415-422.

11. Pereira LJ, Gaviao MBD, Bonjardim LR, Castelo PM, Van Der Bilt A. Muscle thickness, bite force, and cranio-facial dimensions in adolescents with signs and symptoms of temporomandibular dysfunction. Eur J Orthod 2007;29:7278.

12. Farella M, Bakke M, Michelotti A, Rapuano A, Martina R. Masseter thickness, endurance and exercise-induced pain in subjects with different vertical cranio-facial morphology. Eur J Oral Sci 2003;111:183-188.

13. Shinogaya T, Bakke M, Thomsen CE, Vilmann A, Sodeyama A, Matsumoto M. Effects of ethnicity, gender and age on clenching force and load distribution. Clin Oral Invest 2001;5:63-68.

14. Pereira-Cenci T, Pereira LJ, Cenci MS, Bonachela WC, Del Bel Cury AA. Maximal bite force and its association with temporomandibular disorders. Braz Dent J 2007;18:65-68.

15. Bakke M, Holm B, Jensen BL, Michler L, Moller E. Unilateral, isometric bite force in 8-68 year old women and men related to occlusal factors. Scand J Dent Res 1990;98:149158.

16. Shinogaya T, Bakke M, Thomsen CE, Vilmann A, Matsumoto $M$. Bite force and occlusal load in healthy young subjects - a methodological study. Eur J Prosthodont Restor Dent 2000;8:11-15.

17. Waltimo A, Könönen M. A novel bite force recorder and maximal isometric bite force values for healthy young adults. Scand J Dent Res 1993;101:171-175.
18. Bonakdarchian M, Askari N, Askari M. Effect of face form on maximal molar bite force with natural dentition. Arch Oral Biol 2009;54:201-204.

19. Olthoff LW, Van Der Glas W, Van Der Blit A. Influence of occlusal vertical dimension on the masticatory performance during chewing with maxillary splints. J Oral Rehabil 2007;34:560-565.

20. Pizolato RA, Gavião MBD, Berretin-Felix G, Sampaio ACM, Junior AST. Maximal bite force in young adults temporomandibular disorders and bruxism. Braz Oral Res 2007;21:278-283.

21. Braun S, Freudenthaler JW, Hönigle K. A study of maximum bite force during growth and development. Angle Orthod 1996;66:261-264.

22. Ferrario VF, Sforza C, Serrao G, Dellavia C, Tartagilia GM. Single tooth bite forces in healthy young adults. J Oral Rehabil 2004;31:18-22.

23. Wichelhaus A, Hüffmeier S, Sander FG. Dynamic functional force measurements on an anterior bite plane during the night. J Orofac Orthop 2003;64:417-425.

24. Kleinfelder JW, Ludwig K. Maximal bite force in patients with reduced periodontal tissue support with and without splinting. J Periodontol 2002;73:1184-1187.

25. Takeuchi N, Yamamoto T. Correlation between periodontal status and biting force in patients with chronic periodontitis during the maintenance phase of theraphy. J Clin Periodontol 2008;35:215-220.

26. Alkan A, Keskiner I, Arici S, Sato S. The effect of periodontitis on biting abilities. J Periodontol 2006;77:1442-1445.

27. Williams WN, Low SB, Cooper WR, Cornell CE. The effect of periodontal bone loss on bite force discrimination. J Periodontol 1987;58;236-239.

28. Morita M, Nishi K, Kimura T, Fukushima M, Watanabe T, Yamashita F, Zhou R, Yang J, Xu X. Correlation between periodontal status and biting ability in Chinese adults population. J Oral Rehabil 2003;30:260-264.

29. Laurell L, Lundgren D. Periodontal ligament areas and occlusal forces in dentitions restored with cross-arch bilateral end abutment bridges. J Clin Periodontol 1985;12:850860.

30. Kogawa EM, Calderon PS, Laurus JRP, Araujo CRP, Conti PCR. Evaluation of maximal bite force in temporomandibular disorders patients. J Oral Rehabil 2006;33:559-565.

31. Sonnesen L, Bakke M, Solow B. Temporomandibular disorders in relation to cranio-facial dimensions, head posture and bite force in children selected for orthodontic treatment. Eur J Orthod 2001;23:179-192.

32. Pereira LJ, Pastore MG, Bonjardim LR, Castelo PM, Gavião MBD. Molar bite force and its correlation with signs of temporomandibular dysfunction in mixed and permanent dentition. J Oral Rehabil 2007;34:759-766. 
33. Cosme DC, Baldisserotto SM, Canabarro Sde A, Shinkai RS. Bruxism and voluntary maximal bite force in young dentate adults. Int J Prosthodont 2005;18:328-332.

34. Lobbezoo F, Lavigne GJ. Do bruxism and temporomandibular disorders have a cause and effect relationship? $J$ Orofacial Pain 1997;11:15-23.

35. Gibbs CH, Mahan PE, Mauderli A, Lundeen HC, Walsh EK. Limits of human bite strength. J Prosthet Dent 1986;56:226229.

36. Babic JZ, Panduric J, Jerolimov V, Mioc M, Pizeta I, Jakovac $M$. Bite force in subjects with complete dentition. Coll Antropol 2002;26: 293- 302.

37. Lasilla V, Holmlund I, Koivumaa KK. Bite force and its correlations in different denture types. Acta Odontol Scand 1985;43:127-132.

38. Hidaka O, Iwasaki M, Saito M, Morimoto T. Influence of clenching intensity on bite force balance, occlusal contact area, and average bite pressure. J Dent Res 1999;78:13361344.

39. Kampe T, Haraldson T, Hannerz H, Carlsson GE. Occlusal perception and bite force in young subjects with and without dental fillings. Acta Odontol Scand 1987;45:101-107.

40. Miyaura K, Morita M, Matsuka Y, Yamashita A, Watanabe T. Rehabilitation of biting abilities in patients with different types of dental prostheses. J Oral Rehabil 2000;27:10731076.

41. Fontijn-Tekamp FA, Slagter AP, Van Der Bilt A, Van T Hof MA, Witter DJ, Kalk W, Jansen JA. Biting and chewing in overdentures, full dentures, and natural dentitions. J Dent Res 2000;79:1519-1524.

42. Ortuḡ G. A new device for measuring mastication force. Ann Anat 2002;184:393-396.

43. Takeuchi H, Ikeda T, Clark GT. A piezoelectric film-based intrasplint detection method for bruxism. J Prosthet Dent 2001;86:195-202.

44. Linderholm $H$, Wennström A. Isometric bite force and its relation to general muscle forge and body build. Acta Odontol Scand 1970;28:679-689.

45. Uzeda SQ, Alonso LG, Guimaraes AS, Smith RL. Evaluation of mandibular dynamics and bite force in myofascial pain follow-up. Eur J Anat 2006;10:31-36.

46. Baba K, Clark GT, Watanabe T, Ohyama T. Bruxism force detection by a piezoelectric film based recording device in sleeping humans. J Orofac Pain 2003;17:58-64.

47. Floystrand F, Kleven E, Oilo G. A novel miniature bite force recorder and its clinical application. Acta Odontol Scand 1982;40:209-214.

48. Van Eijden TM, Koolstra JH, Brugman P, Weijs WA. A feedback method to determine the three-dimensional biteforce capabilities of the human masticatory system. J Dent Res 1988;67:450-454.
49. Van Eijden TM. Jaw muscle activity in relation to the direction and point of application of bite force. J Dent Res 1990;69:901-905

50. Paphangkorakit J, Osborn JW. Effect of jaw opening on the direction and magnitude of human incisal bite forces. $J$ Dent Res 1997;76:561-567.

51. Nishigawa K., Bando E., Nakano M. Quantitative study of bite force during sleep associated bruxism. J Oral Rehabil $2001 ; 28: 485-491$

52. Schindler HJ, Türp JC, Blaser R, Lenz J. Differential activity patterns in the masseter muscle under simulated clenching and grinding forces. J Oral Rehabil 2005;32:552-563.

53. Tortopidis D, Lyons MF, Baxendale RH. Bite force, endurance and masseter muscle fatigue in healthy edentulous subjects and those with TMD. J Oral Rehabil 1999;26:321328.

54. Kikuchi M, Korioth TW, Hannam AG. The association among occlusal contacts, clenching effort, and bite force distribution in man. J Dent Res 1997;76:1316-1325.

55. Burnett CA, Fartash L, Murray B, Lamey PJ. Masseter and temporalis muscle EMG levels and bite force in migraineurs. Headache 2000;40:813-817.

56. Fogle LL, Glaros AG. Contributions of facial morphology, age, and gender to EMG activity under biting and resting conditions: A canonical correlation analysis. J Dent Res 1995; 74:1496-1500.

57. Okiyama S, Ikebe K, Nokubi T. Association between masticatory performance and maximal occlusal force in young men. J Oral Rehabil 2003;30:278-282.

58. Sato S, Ohta M, Sawatari M, Kawamura H, Motegi K. Occlusal contact area, occlusal pressure, bite force, and masticatory efficiency in patients with anterior disc displacement of the temporomandibular joint. J Oral Rehabil 1999;26:906-911.

59. Kumagai H, Suzuki T, Hamada T, Sondang P, Fujitani M, Nikawa $\mathrm{H}$. Occlusal force distribution on the dental arch during various levels of clenching. J Oral Rehabil 1999;26:932935.

60. Shinogaya T, Tanaka Y, Toda S, Hayakawa I. A new approach to evaluate occlusal support by analyzing the center of the bite force. Clin Oral Investig 2002;6:249-256.

61. Zhang X, Hans MG, Graham G, Kirchner HL, Redline S. Correlations between cephalometric and facial photographic measurements of cranio-facial form. Am J Orthod Dentofacial Orthop 2007;131:67-71.

62. Shinogaya T, Bakke M, Thomsen CE, Vilmann A, Sodeyama A, Matsumoto M. Effects of ethnicity, gender and age on clenching force and load distribution. Clin Oral Investig 2001;5:63-68 
63. Tortopidis D, Lyons MF, Baxendle RH, Gilmour WH. The variability of bite force measurements between sessions, in different positions within the dental arch. J Oral Rehabil 1998;25:681-686.

64. Van Eijden TM. Biomechanics of the mandible. Crit Rev Oral Biol Med 2000;11:123-136.

65. Waltimo A, Könönen M. Bite force on single as opposed to all maxillary front teeth. Scand J Dent Res 1994;102:372375.

66. Lindauer SJ, Gay T, Rendell J. Effect of jaw opening on masticatory muscle EMG-force characteristics. J Dent Res 1993;72:51-55.

67. Mackenna BR, Türker KS. Jaw separation and maximum incising force. J Prosthet Dent 1983;49:726-730.

68. Manns A, Miralles R, Palazzi C. EMG, bite force, and elongation of the masseter muscle under isometric voluntary contractions and variations of vertical dimension. J Prosthet Dent 1979;42:674-682. 